KLEIST-JAHRBUCH 2000 


\title{
KLEIST-JAHRBUCH 2000
}

\author{
Im Auftrag des Vorstandes \\ der Heinrich-von-Kleist-Gesellschaft \\ herausgegeben von \\ Günter Blamberger \\ (verantwortlich für Abhandlungen), \\ Sabine Doering und Klaus Müller-Salget \\ (verantwortlich für Rezensionen)
}

VERLAG J.B. METZLER STUTTGART $\cdot$ WEIMAR 


\section{Anschrift der Redaktion:}

Ingo Breuer (verantwortlicher Redakteur), Eike Behrendt, Bernhard Dotzler, Andrea Heuser, Dominik Paß Universität zu Köln, Institut für deutsche Sprache und Literatur, Albertus-Magnus-Platz, D-50923 Köln

\section{Die Deutsche Bibliothek - CIP-Einheitsaufnabme}

Kleist-Jahrbuch ... / - Stuttgart: Metzler. Erscheint jährlich. - Früher im Verl. E. Schmidt, Berlin. Aufnahme nach 1990 (1991) ISSN 0722-8899 1990 (1991) Verl.-Wechsel

ISBN 978-3-476-01792-5

ISBN 978-3-476-02719-1 (eBook)

DOI 10.1007/978-3-476-02719-1

Dieses Werk einschließlich aller seiner Teile ist urheberrechtlich geschützt. Jede Verwertung außerhalb der engen Grenzen des Urheberrechtsgesetzes ist ohne Zustimmung des Verlages unzulässig und strafbar. Das gilt insbesondere für Vervielfältigungen, Übersetzungen, Mikroverfilmungen und die Einspeicherung und Verarbeitung in elektronischen Systemen.

(C) 2000 Springer-Verlag GmbH Deutschland Ursprünglich erschienen bei Verlag J. B. Metzlersche Verlagsbuchhandlung und Carl Ernst Poeschel Verlag GmbH in Stuttgart 2000

www.metzlerverlag.de info@metzlerverlag.de 


\section{INHALT}

\section{Abbandlungen}

Christian Moser: Angewandte Kontingenz. Fallgeschichten bei Kleist und

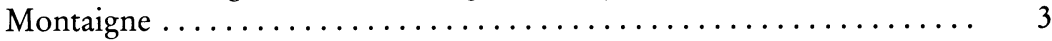

Walburga Hülk: Natur und Fremdheit bei Rousseau und Kleist $\ldots \ldots \ldots \ldots 33$

Claudia Liebrand: Pater semper incertus est. Kleists \Marquise von O... mit

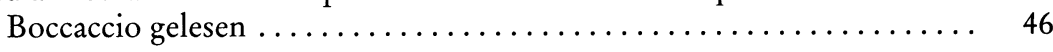

Pamela Moucha: Verspätete Gegengabe. Gabenlogik und Katastrophenbewältigung in Kleists $>$ Erdbeben in Chili $\ldots \ldots \ldots \ldots \ldots \ldots \ldots \ldots 61$

Michael Wetzel: Geben und Vergeben. Vorüberlegungen zu einer Neudeutung der Ambivalenzen bei Kleist $\ldots \ldots \ldots \ldots \ldots \ldots \ldots \ldots$

Wolfgang Pircher: Geld, Pfand und Rache. Versuch über ein Motiv bei

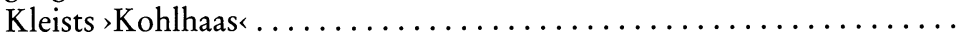

Adam Soboczynski: Die Impotenz des Händlers und das Geheimnis einer trefflichen Frau. Ökonomie und Verstellungen in Kleists Novelle >Der

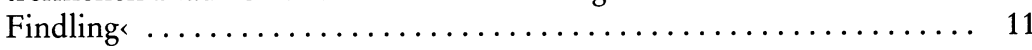

Sibylle Peters: Von der Klugheitslehre des Medialen. (Eine Paradoxe.) Ein Vorschlag zum Gebrauch der >Berliner Abendblätter . . . . . . . . . 136

Heiko Christians: Mißhandlungen der Fabel. Eine kommunikologische Lektüre von Heinrich von Kleists >Michael Kohlhaas $(1810)$. . . . . . . 161

Georg Mein: Identität und Äquilibration. Von Metaphern und Goldwaagen bei Heinrich von Kleist ............................ 180

Alison Lewis: Der Zwang zum Genießen. Männliche Gewalt und der weibliche Körper in drei Prosatexten Kleists 


\section{Rezensionen}

Bernd Hamacher: »Rühreier« oder »Erisäpfel«? (über: Kleists Dramen. Hg. von Walter Hinderer / Kleists Erzählungen. Hg. von Walter Hinderer)

Joachim Pfeiffer: Mythos und Mythoskritik bei Heinrich von Kleist (über: Jörg Ennen, Götter im poetischen Gebrauch. Studien zu Begriff und Praxis der antiken Mythologie um 1800 und im Werk H. v. Kleists / Doris Claudia Borelbach, Mythos-Rezeption in Heinrich von Kleists Dramen)

Monika Meister: Der mißlungene Versuch einer Bühnengeschichte der Dramen Kleists (über: Norman Orzechowski, Kleists Dramen in den Bühnendekorationen des 19. und 20. Jahrhunderts) $\ldots \ldots \ldots \ldots \ldots \ldots$

Dieter Burdorf: Predigtkunst und Kunstpredigt. Zum Verhältnis von Romantik und Homiletik (über: Nicholas Saul, »Prediger der neuen romantischen Clique«. Zur Interaktion von Romantik und Homiletik um 1800)

Mathias Mayer: Erfolgreiches Scheitern beim Erzählen (über: Michael Boehringer, The Telling Tactics of Narrative Strategies in Tieck, Kleist, Stifter, and Storm)

Gertrud Rösch: Der Körper, die Revolution und der zerschriebene Diskurs des weißen Mannes (über: Herbert Uerlings, Poetiken der Interkulturalität. Haiti bei Kleist, Seghers, Müller, Buch und Fichte) ..........

Siglenverzeichnis . . ............................. 271

Anschriften der Mitarbeiterinnen und Mitarbeiter .............. 272

Informationen zur Heinrich-von-Kleist-Gesellschaft $\ldots \ldots \ldots \ldots \ldots \ldots .274$ 